\title{
Expression of glioma-associated oncogene 2 (Gli 2) is correlated with poor prognosis in patients with hepatocellular carcinoma undergoing hepatectomy
}

\author{
Dawei Zhang ${ }^{\dagger}$, Liangqi Cao ${ }^{\dagger}$, Yue Li, Haiwu Lu, Xuewei Yang and Ping Xue
}

\begin{abstract}
Background: Our previous studies showed that glioma-associated oncogene (Gli)2 plays an important role in the proliferation and apoptosis resistance of hepatocellular carcinoma (HCC) cells. The aim of this study was to explore the clinical significance of Gli2 expression in HCC.

Methods: Expression of Gli2 protein was detected in samples from 68 paired HCC samples, the corresponding paraneoplastic liver tissues, and 20 normal liver tissues using immunohistochemistry. Correlation of the immunohistochemistry results with clinicopathologic parameters, prognosis, and the expression of E-cadherin, $\mathrm{N}$-cadherin, and vimentin were analyzed.

Results: Immunohistochemical staining showed high levels of Gli2 protein expression in HCC, compared with paraneoplastic and normal liver tissues $(P<0.05)$. This high expression level of $\mathrm{Gli} 2$ was significantly associated with tumor differentiation, encapsulation, vascular invasion, early recurrence, and intra-hepatic metastasis $(P<0.05)$. There was a significantly negative correlation between Gli2 and E-cadherin expression $(r=-0.302, P<0.05)$ and a significantly positive correlation between expression of Gli2 and expression of vimentin $(r=-0.468, P<0.05)$ and $\mathrm{N}$-cadherin $(r=-0.505, P<0.05)$. Kaplan-Meier analysis showed that patients with overexpressed $\mathrm{Gli} 2$ had significantly shorter overall survival and disease-free survival times $(P<0.05)$. Multivariate analysis suggested that the level of Gli2 expression was an independent prognostic factor for HCC.
\end{abstract}

Conclusions: Expression of Gli2 is high in HCC tissue, and is associated with poor prognosis in patients with HCC after hepatectomy.

Keywords: Gli2, Hepatocellular carcinoma, Prognosis, Epithelial-to-mesenchymal transition

\section{Background}

Hepatocellular carcinoma (HCC) is the fifth most common malignancy and the third most common cause of death from cancer worldwide [1,2]. There are an estimated 626,000 to $1,000,000$ new cases annually worldwide, with about half of these occurring in China alone [3,4]. Despite advances in surgical and chemotherapeutic approaches, the survival rate of patients with HCC is as low as 20 to

\footnotetext{
* Correspondence: gyeyxueping@163.com

${ }^{\dagger}$ Equal contributors

Department of Hepatobiliary Surgery, the Second Affiliated Hospital of

Guangzhou Medical College, No. 250, East Changgang Road, Guangzhou 510260, China
}

(c) 2013 Zhang et al.; licensee BioMed Central Ltd. This is an Open Access article distributed under the terms of the Creative Commons Attribution License (http://creativecommons.org/licenses/by/2.0), which permits unrestricted use, distribution, and reproduction in any medium, provided the original work is properly cited.
$50 \%$ at 5 years, even in early-stage $\mathrm{HCC}$ after radical resection $[5,6]$. Recurrence after treatment remains one of the most important causes of poor long-term survival. Prediction of tumor carcinogenesis using molecular prognostic markers might aid in developing more effective therapeutic strategies and therefore result in better prognosis. However, to date, no identified molecular marker has shown unequivocal prognostic utility in HCC.

The Hedgehog (Hh) signaling pathway regulates body patterning, cell differentiation, and proliferation during embryonic development $[7,8]$. In humans, the $\mathrm{Hh}$ signaling pathway consists of three ligands: Shh, Ihh, and Dhh, which can bind to the transmembrane receptor Patched 1 
Table 1 Clinicopathologic characteristics of 68 patients with hepatocellular carcinoma (HCC)

\begin{tabular}{|c|c|}
\hline Variable & Patients, $\mathrm{n}$ \\
\hline \multicolumn{2}{|l|}{ Gender } \\
\hline Male & 53 \\
\hline Female & 15 \\
\hline \multicolumn{2}{|l|}{ Age, years } \\
\hline$\leq 60$ & 43 \\
\hline$>60$ & 25 \\
\hline \multicolumn{2}{|l|}{ Virus infection } \\
\hline HBV & 58 \\
\hline $\mathrm{HCV}$ & 2 \\
\hline None & 8 \\
\hline \multicolumn{2}{|l|}{ AFP, ng/ml } \\
\hline$\leq 200$ & 28 \\
\hline$>200$ & 40 \\
\hline \multicolumn{2}{|l|}{ Cirrhosis } \\
\hline Present & 48 \\
\hline Absent & 20 \\
\hline \multicolumn{2}{|l|}{ Tumor size, mm } \\
\hline$\leq 50$ & 18 \\
\hline$>50$ & 50 \\
\hline \multicolumn{2}{|l|}{ TNM stage } \\
\hline 1 & 12 \\
\hline$\|$ & 33 \\
\hline III & 20 \\
\hline IV & 3 \\
\hline \multicolumn{2}{|l|}{ Tumor differentiation } \\
\hline Well & 16 \\
\hline Moderate & 39 \\
\hline Poor & 13 \\
\hline \multicolumn{2}{|l|}{ Tumor number } \\
\hline Solitary & 54 \\
\hline Multiple & 14 \\
\hline \multicolumn{2}{|l|}{ Tumor encapsulation } \\
\hline Intact & 39 \\
\hline Absent or not intact & 29 \\
\hline \multicolumn{2}{|l|}{ Vascular invasion } \\
\hline Present & 29 \\
\hline Absent & 39 \\
\hline
\end{tabular}

Abbreviations: AFP, alpha fetoprotein; HBV, hepatitis B virus; $\mathrm{HCV}$, hepatitis $\mathrm{C}$ virus; TMN, tumor, node, metastasis.

(Ptch1). Upon ligand binding to Ptch1, Smoothened (Smo) is released, signals are transduced to the nucleus, and these converge on three Gli zinc finger transcription factors: Gli1, Gli2, and Gli3 [9]. Aberrant activation of the Hh pathway has recently been reported in various human cancers, including basal cell carcinoma, gastrointestinal malignancies, and breast, prostate, pancreatic, and lung cancers [10-16]. In addition, the Hh pathway cascade cross-talks with the WNT, EGF/FGF, and TGF- $\beta$ /Activin/ Nodal/BMP signaling cascades, which are implicated in epithelial-to-mesenchymal transition (EMT) through repression of E-cadherin and activation of $\mathrm{N}$-cadherin, therefore, the Hh pathway is associated with invasion and metastasis of tumors [17].

Previous studies have shown that components of the Hh pathway are indicators for poor survival in bladder cancer, oral and esophageal squamous cell carcinoma, and ovarian, colon and breast cancers [18-23]. Of the three Gli transcriptional factors, Gli2 is a strong positive activator of downstream target genes, and it can induce Gli1 expression independent of Hh signaling [24]. The Gli2 protein has been reported to have high expression levels in HCC cell lines and human HCC tissues [25-28]. Our previous work showed that small hairpin (sh)RNAmediated silencing of the Gli2 gene inhibits proliferation by inducing cell-cycle arrest at G1 phase in the HCC SMMC-7721 cell line. Moreover, knockdown of Gli2 enhanced SMMC-7721 to tumor necrosis factor (TNF)related apoptosis-inducing ligand (TRAIL)-induced cell apoptosis via downregulation of c-FLIP and Bcl-2, consequently leading to induction of caspase- 8 or caspase- 9 dependent apoptosis pathway [29]. However, there have been few clinical reports investigating the relationship between Gli2 protein expression and the postoperative survival of patients with HCC, or whether Gli2 is realated to induction of EMT.

In the current study, we examined expression of Gli2 protein in HCC tissue using immunohistochemistry. We also evaluated the relationship of this expression with the clinical characteristics, expression of E-cadherin, $\mathrm{N}$ cadherin, and vimentin, and prognosis to determine whether the level of Gli2 expression could be used to predict prognosis in patients with $\mathrm{HCC}$ after radical hepatectomy.

\section{Methods}

\section{Ethics approval}

The study was approved by the Ethics Committee of the Second Affiliated Hospital of Guangzhou Medical College with the following reference number: GY20080216302. Each patient provided written informed consent before hepatectomy.

\section{Patients and liver specimens}

Samples of primary HCC tissues $(n=68)$ and corresponding paraneoplastic liver tissue (PLT, taken at $20 \mathrm{~mm}$ distance from the tumor margin) were obtained from patients (53 men, 15 women, median age 55 years; range 33-78 years) who underwent curative resection at the Second Affiliated Hospital of Guangzhou Medical College (Guangzhou, China) between February 2004 and July 2007. 

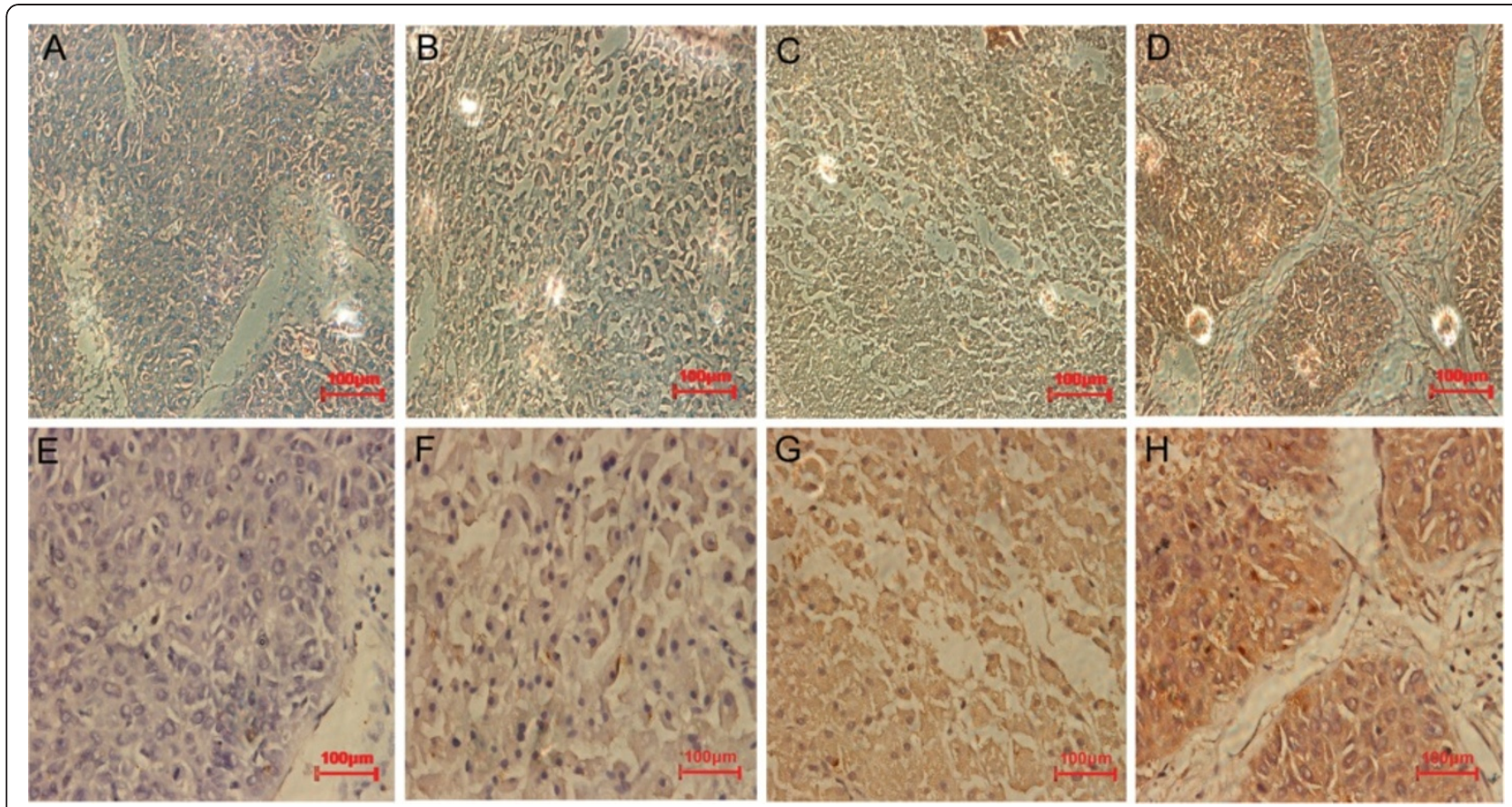

Figure 1 Representative images of Gli2 immunohistochemical staining in human normal liver tissue (NLT), paraneoplastic liver tissue (PLT), and HCC. (A,E) NLT with negative Gli2 expression. (B,F) PLT with week Gli2 expression. (C,G) HCC with moderate Gli2 expression. (D,H) HCC with strong Gli2 expression. Original magnification (A-D) $\times 200$ for $\mathrm{E}-\mathrm{H} \times 400$.

The diagnosis was confirmed by histologic examination. Curative resection was defined as removal of all recognizable tumor tissue with a clear microscopic margin. Specimens were obtained immediately after surgical resection. The patients were not pretreated with radiotherapy or chemotherapy before surgery. The control tissues were 20 samples of normal liver tissue (NLT), which were acquired from patients who had undergone surgery for liver trauma. All specimens were fixed in $10 \%$ formalin, and embedded in paraffin wax for immunohistochemical analysis.

The clinicopathologic variables are shown in Table 1. Tumor size ranged from 32 to $193 \mathrm{~mm}$, with a median of $65 \mathrm{~mm}$. The TNM (tumor, node, metastasis) stage was determined using the American Joint Committee on Cancer/International Union Against Cancer tumor classification system, with 45 patients classified as I or II and 23 as III or IV. Tumor differentiation was classified as follows: 16 tumors were well differentiated, 39 were moderately differentiated, and 13 cases were poorly differentiated.

\section{Immunohistochemistry}

Formalin-fixed, paraffin wax-embedded tissue specimens were obtained. Serial sections $4 \mu \mathrm{m}$ thick were prepared from each sample, then some sections were stained with hematoxylin and eosin for histologic diagnoses of tumor and non-tumor, while other sections were stained for Gli2 using the streptavidin-biotin horseradish peroxidase complex method. For the latter, the tissue sections were dewaxed, rehydrated with a xylene and graded alcohol series, and then incubated in 3\% hydrogen peroxide for 10 minutes to block endogenous peroxidase activity. Optimal antigen retrieval was carried out in citrate buffer ( $\mathrm{pH}$ 6.0) for 10 minutes in a microwave oven to enhance the immunoreactivity, and then sections were incubated in 10\% blocking serum for 30 minutes at $37^{\circ} \mathrm{C}$ to reduce nonspecific binding. Primary anti-Gli2 polyclonal antibodies (Santa Cruz Biotechnology Inc., Santa Cruz, CA, USA) were diluted 1:100, and incubated with the sections at $4^{\circ} \mathrm{C}$ overnight. Subsequently, the secondary antibodies (biotinylated goat anti-rabbit immunoglobulin) and streptavidin peroxidase complex reagent were applied. Finally, the visualization signal was developed with diaminobenzidine (DAB), and the slides were counterstained with hematoxylin. Two investigators blinded to the clinical information evaluated each stained section.

The Gli2 reaction for Gli2 was graded according to the staining intensity $(0,1+, 2+$, and $3+)$. The percentages of Gli2-positive cells were also scored on a four-point scale as $0(0 \%), 1$ ( 1 to $33 \%$ ), 2 (34 to $66 \%$ ), and 3 (67 to $100 \%$ ). The sum of the intensity and percentage scores was used as the final Gli2 protein staining score. The staining 
Table 2 Correlation between Gli2 expression and clinicopathologic characteristics in HCC

\begin{tabular}{|c|c|c|c|c|}
\hline \multirow[t]{2}{*}{ Characteristics } & \multicolumn{2}{|c|}{ Gli2 expression } & \multirow[t]{2}{*}{$x^{2}$} & \multirow{2}{*}{$\begin{array}{l}P \\
\text { value }\end{array}$} \\
\hline & High $(n=43)$ & Low $(n=25)$ & & \\
\hline \multicolumn{5}{|l|}{ Gender } \\
\hline Male & 33 & 20 & 0.097 & 0.755 \\
\hline Female & 10 & 5 & & \\
\hline \multicolumn{5}{|l|}{ Age, years } \\
\hline$\leq 60$ & 29 & 14 & 0.890 & 0.345 \\
\hline$>60$ & 14 & 11 & & \\
\hline \multicolumn{5}{|l|}{ Virus infection } \\
\hline HBV & 35 & 23 & 0.698 & 0.403 \\
\hline $\mathrm{HCV}$ & 2 & 0 & & \\
\hline None & 6 & 2 & & \\
\hline
\end{tabular}

\begin{tabular}{lllll}
\hline AFP $(\mathrm{ng} / \mathrm{ml})$ & & & & \\
\hline$\leq 200$ & 20 & 8 & 1.374 & 0.241 \\
\hline$>200$ & 23 & 17 & & \\
\hline Cirrhosis & & & & \\
\hline Present & 30 & 18 & 0.038 & 0.846 \\
\hline Absent & 13 & 7 & &
\end{tabular}

\begin{tabular}{lllll}
\hline Tumor size, $\mathrm{mm}$ & & & & \\
\hline$\leq 50$ & 26 & 13 & 0.837 & 0.360 \\
\hline$>50$ & 15 & 12 & &
\end{tabular}

TNM stage

\begin{tabular}{lllll}
\hline I or II & 25 & 20 & 3.375 & 0.066 \\
\hline III or IV & 18 & 5 & & \\
\hline Tumor differentiation & & & & \\
\hline Well & 6 & 10 & 6.591 & $0.037^{*}$ \\
\hline Moderate & 28 & 11 & & \\
\hline Poor & 9 & 4 & \\
\hline
\end{tabular}

Tumor number

\begin{tabular}{lllll}
\hline Solitary & 32 & 22 & 1.784 & 0.182 \\
\hline Multiple & 11 & 3 & & \\
\hline Tumor encapsulation & & & & \\
\hline Intact & 11 & 15 & 7.930 & $0.005^{*}$ \\
\hline Absent or not intact & 32 & 10 & & \\
\hline Vascular invasion & & & & \\
\hline Present & 23 & 6 & 5.620 & $0.018^{*}$ \\
\hline Absent & 20 & 19 & & \\
\hline
\end{tabular}

\begin{tabular}{lllll}
\hline Early recurrence & & & \\
\hline Yes & 25 & 8 & 4.324 & $0.038^{*}$ \\
\hline No & 18 & 17 & & \\
\hline Intra-hepatic metastasis & 16 & 5 & 4.997 & $0.025^{*}$ \\
\hline Present & 17 & 20 & & \\
\hline Absent &
\end{tabular}

Variables are presented as number and tested by $X^{2}$ or Fisher's exact test. ${ }^{*} P<0.05$. pattern was defined as follows: 0 , negative; 1 to 2 , weak; 3 to 4 , moderate; 5 to 6 , strong $[30,31]$. For statistical analyses, scores of 0 to 2 were considered 'low expression' and scores of 3 to 6 were considered 'high expression'.

\section{Follow-up}

The follow-up period was defined as the interval from the date of operation to that of the last visit or the patient's death. Deaths from other causes were treated as censored cases. After discharge, patients were followed up every 3 months during the first 2 years and every 6 months thereafter by clinical examination, including measurement of alpha fetoprotein, ultrasonography and computed tomography (CT). Times of tumor recurrence were recorded, based on the time of recurrences from the date of hepatectomy, they were classified as early ( $\leq 1$ year) and late ( $>1$ year) recurrences. Patients who developed recurrence were treated with radiofrequency ablation, percutaneous ethanol injection, or transcatheter arterial chemoembolization, or with re-resection when necessary. Disease-free survival (DFS) was defined as the interval from the operation date to recurrence, and overall survival (OS) was defined as the interval between the operation date and death. Follow-up was performed using email and telephone.

\section{Statistical analysis}

The $\chi^{2}$ text or Fisher's exact test was used to analyze the relationship between Gli2 expression and the clinicopathologic characteristics. DFS and OS were calculated using the Kaplan-Meier method, and differences were assessed using the log-rank test. The Cox proportional hazard regression model was used to examine associations between the various prognostic factors and survival. For all tests, a value of $P<0.05$ was considered significant. All statistics were calculated using SPSS software (version 16.0; SPSS Inc., Chicago, IL, USA).

\section{Results}

\section{Expression of Gli2}

Follow-up data were obtained for all 68 patients. All patients were followed up until November 2010. The follow-up time ranged from 6 to 79 months, with a median follow-up time of 52 months.

The immunohistochemical staining identified the Gli2 location in the cytoplasm and/or nucleus of tumor cells, mainly in the cytoplasm. Gli2 expression in NLT from hemangiomas and PLT were negative or weakly positive (Figure 1A,B,E,F), and mainly moderately or strongly positive in HCC (Figure 1C,D,G,H). Overall, high expression of Gli2 was recorded in $63.2 \%$ (43/68), $11.8 \%$ $(8 / 68)$, and $10 \%(2 / 20)$ of the biopsies in HCC, PLT, and NLT samples, respectively. There were significant differences for Gli2 staining between NL and HCC $(P<0.05)$, 


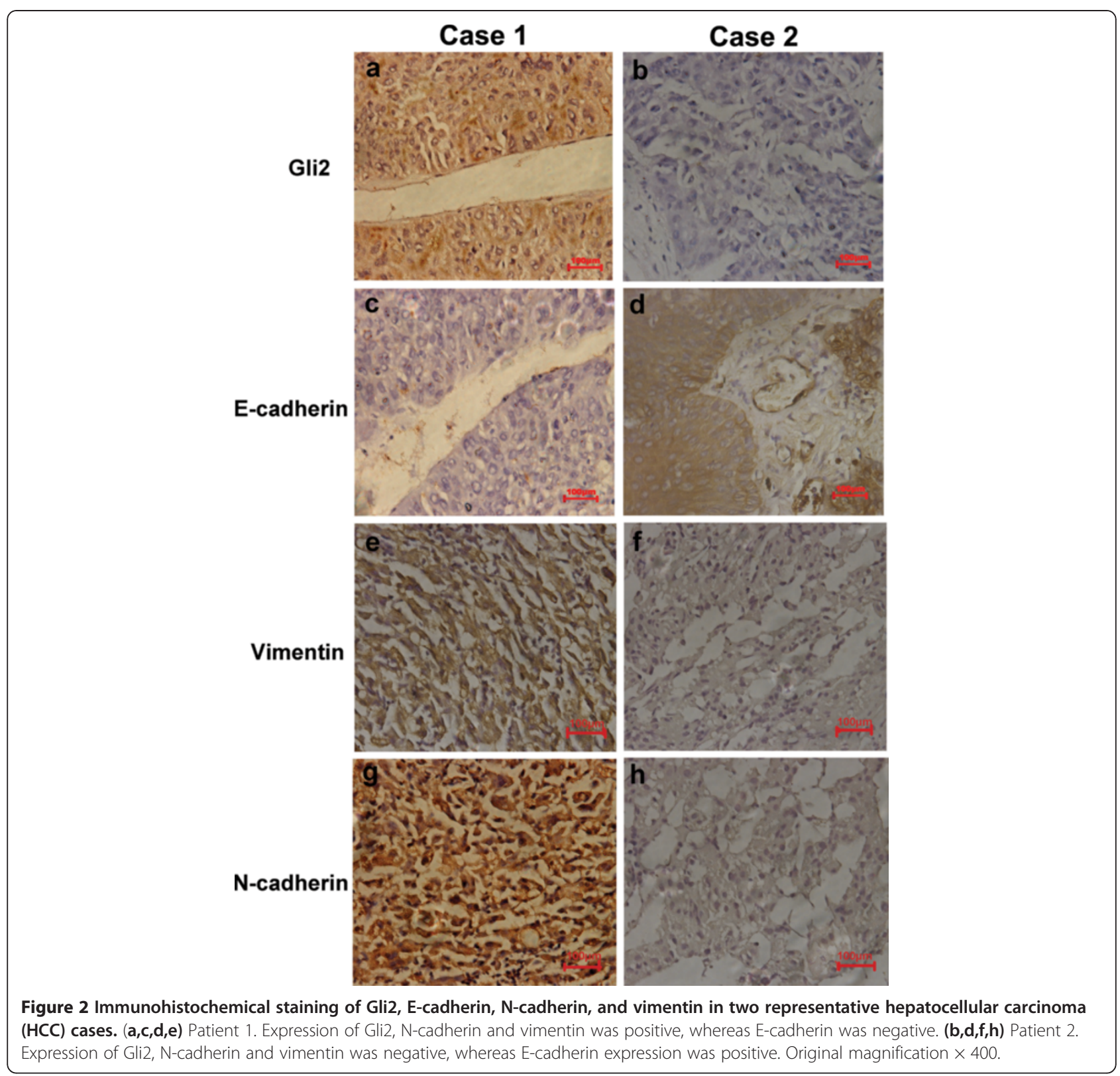

and between PLT and HCC $(P<0.05)$, but there was no significant difference between NL and PLT $(P>0.05)$.

Immunohistochemistry analysis of Gli2 expression and its relationship with clinicopathologic characteristics

Correlation between the expression levels of Gli2 in HCC and various clinicopathologic variables are summarized in Table 2. A high expression level for Gli2 protein was significantly correlated with tumor differentiation, encapsulation, vascular invasion, early recurrence, and intra-hepatic metastasis $(P<0.05)$. There was no significant correlation between Gli2 expression and gender, age, hepatitis virus serology, AFP level, cirrhosis, tumor size, TNM stage, or number of tumors $(P>0.05)$.

Association between E-cadherin, N-cadherin, vimentin, and Gli2 expression in hepatocellular carcinoma

Given the role of Hedgehog signaling in inducing EMT through multiple regulators, such as Snail, ZEB1, ZEB2, Twist1, Twist2, and FOXC2, [17] we analyzed the relationship between Gli2 expression and that of E-cadherin, $\mathrm{N}$-cadherin and vimentin in the $68 \mathrm{HCC}$ samples. Expression of Gli2 was negatively correlated with E-cadherin, and positively correlated with $\mathrm{N}$-cadherin and vimentin. Tissue with high expression levels for Gli2 also 
Table 3 Association between expression of Gli2 and expressin of $\mathrm{E}$-cadherin, $\mathrm{N}$-cadherin and vimentin in patients with hepatocellular carcinoma

\begin{tabular}{|c|c|c|c|c|c|}
\hline \multirow{2}{*}{$\begin{array}{l}\text { Expression } \\
\text { level }\end{array}$} & \multicolumn{2}{|c|}{ Gli2 expression } & \multirow[t]{2}{*}{$x^{2}$} & \multirow{2}{*}{$\begin{array}{l}P \\
\text { value }\end{array}$} & \multirow{2}{*}{$\begin{array}{l}\text { Association } \\
\text { coefficient }(r)\end{array}$} \\
\hline & High & Low & & & \\
\hline \multicolumn{6}{|l|}{ E-cadherin } \\
\hline High & 12 & 31 & 6.801 & $0.009^{*}$ & -0.302 \\
\hline Low & 15 & 10 & & & \\
\hline \multicolumn{6}{|l|}{ Vimentin } \\
\hline High & 35 & 8 & 6.801 & $0.009^{*}$ & 0.468 \\
\hline Low & 7 & 18 & & & \\
\hline \multicolumn{6}{|l|}{ N-cadherin } \\
\hline High & 37 & 6 & 23.324 & $0.001^{*}$ & -0.505 \\
\hline Low & 7 & 18 & & & \\
\hline
\end{tabular}

${ }^{*} P<0.05$.

had high expression levels for N-cadherin $(r=-0.505$, $P<0.05)$ and vimentin $(r=-0.468, P<0.05)$, but low expression of E-cadherin $(r=-0.302, P<0.05) \mathrm{d}$ Representative images are shown in Figure 2 and the statistical results are listed in Table 3.

\section{Survival analysis}

We assessed the Kaplan-Meier estimates for the group with high Gli2 expression and the group with low Gli2 expression. Our results indicated that the median OS for the two groups were 17 and 58 months, respectively. The log-rank test showed as significant difference between the two survival curves; the OS rate of the group with high Gli2 expression was lower than that of the group with low Gli2 expression $(P<0.05)$. Similarly, the median DFS time for the two groups was 8 and 30 months, respectively, and patients with high Gli2 expression of Gli2 had a significantly shorter DFS compared with the patients with low Gli2 expression $(P<0.05)$ (Figure 3$)$.

\section{Univariate and multivariate analyses for the prognostic value of Gli2 expression}

In univariate analysis, the factors significantly associated with OS were tumor size, TNM stage, differentiation, tumor encapsulation, vascular invasion, and Gli2 expression, and those significantly associated with DFS were tumor size, tumor encapsulation, vascular invasion, and Gli2 expression (Table 4). Furthermore, multivariate Cox proportional hazards regression analysis indicated that in patients with HCC, tumor size, vascular invasion, and Gli2 expression were independent prognostic factors for OS, while tumor encapsulation, vascular invasion, and Gli2 expression were independent predictors for DFS $(P<0.05)$ (Table 5).

\section{Discussion}

Gli2, a transcription factor of the Hh pathway, regulates expression of downstream target genes, including Gli1, Bcl-2, c-FLIP, cyclin D1, c-Myc and vascular endothelial growth factor (VEGF) [32-35], which has previously been implicated in the development of various human tumors, such as medulloblastomas, basal cell carcinoma, prostate and breast cancer, and HCC [28,36-38], Gli2 was reportedly overexpressed and related to poor survival of patients with pediatric medulloblastoma. Although high expression levels of the Gli2 protein has been reported in HCC cell lines and tissues [25,26,39], the association between Gli2 expression and prognosis in patients with HCC has not been elucidated. To analyze the role of Gli2 in HCC, we carried out immunohistochemical staining and found higher levels of Gli2 protein in HCC tissues compared with PLT and NLT.

Analyzing the association of Gli2 expression with pathologic characteristics in 68 patients with HCC identified a significant correlation of Gli2 expression with tumor differentiation, encapsulation, vascular invasion, early recurrence, and intra-hepatic metastasis. Kaplan-Meier analysis showed that patients with HCC who had high expression
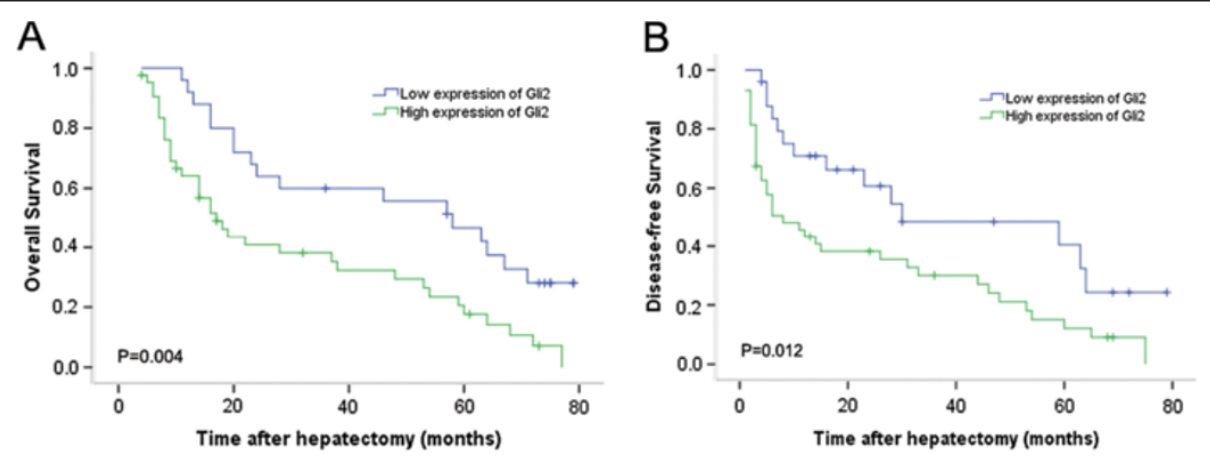

Figure 3 Overall survival (OS) curves of patients with hepatocellular carcinoma (HCC) undergoing hepatectomy were compared between the groups with high and low expression of Gli2. (A) OS; (B) disease-free survival. 
Table 4 Univariate analysis of factors associated with overall survival (OS) and disease-free survival (DFS) of 68 patients with hepatocellular carcinoma

\begin{tabular}{|c|c|c|}
\hline \multirow[t]{2}{*}{ Factor } & \multicolumn{2}{|l|}{$P$ value } \\
\hline & os & DFS \\
\hline Gender (male versus female) & 0.564 & 0.867 \\
\hline Age ( $\leq 60$ versus $>60$ years) & 0.430 & 0.682 \\
\hline Virus (HBV versus HCV and none) & 0.410 & 0.247 \\
\hline AFP ( $\leq 200$ versus $>200$ ng/ml) & 0.909 & 0.626 \\
\hline Cirrhosis (absent versus present) & 0.313 & 0.551 \\
\hline Tumor size ( $\leq 50$ versus $>50 \mathrm{~mm})$ & $0.005^{*}$ & 0.001 \\
\hline TNM stage (I to || versus III to IV) & $0.034^{*}$ & 0.056 \\
\hline Differentiation (well and moderate versus poor) & $0.011^{*}$ & 0.110 \\
\hline Tumor number (solitary versus multiple) & 0.401 & 0.741 \\
\hline Tumor encapsulation (intact versus absent or not intact) & $0.011^{*}$ & 0.009 \\
\hline Vascular invasion (absent versus present) & $0.003^{*}$ & 0.001 \\
\hline Gli2 expression (low versus high) & $0.005^{*}$ & 0.017 \\
\hline
\end{tabular}

Abbreviations: AFP, alpha fetoprotein; $\mathrm{HBV}$, hepatitis $\mathrm{B}$ virus; $\mathrm{HCV}$, hepatitis $\mathrm{C}$ virus; TMN, tumor, node, metastasis.

$* P<0.05$.

of Gli2 had significantly worse prognosis than those with low expression, both for OS and DFS. Multivariate analysis showed that Gli2 was an independent prognostic factor for both recurrence and survival in patients with HCC after hepatectomy. Meanwhile, tumor size and vascular invasion were also independent prognostic factors for OS, while tumor encapsulation and vascular invasion were independent prognostic factors for DFS. Therefore, the level of protein expression of Gli2, a novel molecular biomarker, may be a powerful prognostic indicator for recurrence and survival of patients with HCC.

Our results showed that high expression of Gli2 was associated with vascular invasion, early recurrence, and intra-hepatic metastasis in patients with $\mathrm{HCC}$, suggesting that overexpression of Gli2 contributes to progression of HCC. Furthermore, the immunohistochemical results showed a significantly negative correlation between Gli2 and E-cadherin expression and a significantly positive correlation between Gli2 expression and both vimentin and $\mathrm{N}$-cadherin expression. We speculate that Gli2 could play an important role in invasion and metastasis of HCC by inducing EMT.

In previous studies, EMT was characterized by decreased cell adhesion and increased motility, which was accompanied by downregulation of E-cadherin and upregulation of vimentin and $\mathrm{N}$-cadherin [40,41]. Zheng et al. found that Gli1 protein expression was positively correlated with Shh and S100a4, and negatively correlated with E-cadherin [42]. EMT is regulated by several transcription factors, including Snail, ZEB1, ZEB2, Twist1, and Twist2, each of which bind to the E-
Table 5 Multivariate Cox regression analysis

\begin{tabular}{llll}
\hline Factor & $\begin{array}{l}\boldsymbol{P} \\
\text { value }\end{array}$ & $\begin{array}{l}\text { Hazard } \\
\text { ratio }\end{array}$ & $\begin{array}{l}\mathbf{9 5 \%} \text { Confidence } \\
\text { interval }\end{array}$ \\
\hline Overall survival & & & \\
\hline Tumor size & $0.002^{*}$ & 2.509 & 1.414 to 4.454 \\
\hline TNM stage & NS & - & - \\
\hline Differentiation & NS & - & - \\
\hline $\begin{array}{l}\text { Tumor } \\
\text { encapsulation }\end{array}$ & NS & - & - \\
\hline Vascular invasion & $0.004^{*}$ & 2.305 & 1.304 to 4.073 \\
\hline Gli2 expression & $0.007^{*}$ & 2.239 & 1.244 to 4.028 \\
\hline Disease-free survival & & & \\
\hline Tumor size & NS & - & - \\
\hline $\begin{array}{l}\text { Tumor } \\
\text { encapsulation }\end{array}$ & $0.001^{*}$ & 2.763 & 1.534 to 4.977 \\
\hline Vascular invasion & $0.002^{*}$ & 2.516 & 1.397 to 4.533 \\
\hline Gli2 expression & $0.042^{*}$ & 1.917 & 1.025 to 3.584 \\
\hline Abbrevalions: AFP, alpha fetoprt
\end{tabular}

Abbreviations: AFP, alpha fetoprotein; NS, not significant. ${ }^{*} P<0.05$.

cadherin promoter region and repress its transcription [43-49]. The Hh pathway induces JAG2 upregulation for Notch-CSL-mediated Snal1 upregulation, and also induces transforming growth factor (TGF)- $\beta$ secretion for ZEB1 and ZEB2 upregulation via the TGF- $\beta$ receptor and nuclear factor (NF)- $\mathrm{KB}$. TGF- $\beta$-mediated downregulation of the microRNAs R-141, 200a, 200b, 200c, 205 , and 429 results in upregulation of the ZEB1 and ZEB2 proteins. Activation of $\mathrm{Hh}$ signaling indirectly leads to EMT through Notch, TGF- $\beta$ signaling cascades, and regulatory networks of microRNA [17]. Recently, Alexaki et al. investigated the role of Gli2 in the invasion and metastasis of melanoma and found that increased expression of Gli2 was associated in melanoma cell lines with loss of E-cadherin expression and increased capacity to invade a protein gel (Matrigel) and to form bone metastases in mice [50]. Taken together, these results indicate that Gli2 might lead to the increased early recurrence and development of intrahepatic metastases of HCC by induction of EMT.

\section{Conclusion}

Our current findings indicate for the first time that the expression level of Gli2 is high in HCC tissue, and this high expression shows a significant association with poor clinical outcome after hepatectomy and a more aggressive tumor phenotype because it induces EMT changes. However, further studies are needed to investigate the biochemical mechanisms by which Gli2 induces EMT of HCC. 


\section{Competing interests}

No conflict of interests to declare.

\section{Authors' contributions}

Study conception and design: DZ and PX. Drafting of manuscript: LC. Acquisition of data: YL. Surgical procedures and management of the patients: HL. Analysis and interpretation of data: XY. All authors read and approved the final manuscript.

\section{Acknowledgments}

We thank the Medical Research Center, the Sun Yat-Sen Memorial Hospital of Sun Yat-Sen University for providing experimental instruments and equipment. This work was supported by the Foundation of Science and Technology Planning Project of Guangdong Province, China (2010B031600141)

Received: 15 September 2012 Accepted: 6 January 2013

Published: 29 January 2013

\section{References}

1. Llovet JM, Burroughs A, Bruix J: Hepatocellular carcinoma. Lancet 2003, 362:1907-1917.

2. Page JM, Harrison SA: NASH and HCC. Clin Liver Dis 2009, 13:631-647.

3. Jemal A, Bray F, Center MM, et al: Global cancer statistics. CA Cancer J Clin 2011, 61:69-90.

4. Parkin DM, Bray F, Ferlay J, et al: Global cancer statistics, 2002. CA Cancer J Clin 2005, 55:74-108.

5. Hubert C, Sempoux C, Rahier J, et al: Prognostic risk factors of survival after resection of hepatocellular carcinoma. Hepatogastroenterology 2007 54:1791-1797.

6. Sherman M: Recurrence of hepatocellular carcinoma. N Engl J Med 2008, 359:2045-2047.

7. Ingham PW, McMahon AP: Hedgehog signaling in animal development: paradigms and principles. Genes Dev 2001, 15:3059-3087.

8. Ruizi Altaba A, Sanchez P, Dahmane N: Gli and hedgehog in cancer: tumours, embryos and stem cells. Nat Rev Cancer 2002, 2:361-372.

9. Lum L, Beachy PA: The Hedgehog response network: sensors, switches, and routers. Science 2004, 304:1755-1759.

10. Berman DM, Karhadkar SS, Maitra A, et al: Widespread requirement for Hedgehog ligand stimulation in growth of digestive tract tumours. Nature 2003, 425:846-851.

11. Ji J, Kump E, Wernli $M$, et al: Gene silencing of transcription factor Gli2 inhibits basal cell carcinomalike tumor growth in vivo. Int J Cancer 2008, 122:50-56.

12. Kubo M, Nakamura M, Tasaki A, et al: Hedgehog signaling pathway is a new therapeutic target for patients with breast cancer. Cancer Res 2004, 64:6071-6074.

13. Thayer SP, di Magliano MP, Heiser PW, et al: Hedgehog is an early and late mediator of pancreatic cancer tumorigenesis. Nature 2003, 425:851-856.

14. Thiyagarajan S, Bhatia N, Reagan-Shaw S, et al: Role of GLI2 transcription factor in growth and tumorigenicity of prostate cells. Cancer Res 2007, 67:10642-10646.

15. Velcheti V, Govindan R: Hedgehog signaling pathway and lung cancer. J Thorac Oncol 2007, 2:7-10.

16. Von Hoff DD, LoRusso PM, Rudin CM, et al: Inhibition of the hedgehog pathway in advanced basal-cell carcinoma. N Engl J Med 2009, 361:1164-1172.

17. Katoh Y, Katoh M: Hedgehog signaling, epithelial-to-mesenchymal transition and miRNA (review). Int J Mol Med 2008, 22:271-275.

18. He HC, Chen $\mathrm{JH}$, Chen XB, et al: Expression of hedgehog pathway components is associated with bladder cancer progression and clinical outcome. Pathol Oncol Res 2012, 18:349-355.

19. Liao $X$, Siu MK, Au CW, et al: Aberrant activation of hedgehog signaling pathway in ovarian cancers: effect on prognosis, cell invasion and differentiation. Carcinogenesis 2009, 30:131-140.

20. Mori Y, Okumura T, Tsunoda S, et al: Gli-1 expression is associated with lymph node metastasis and tumor progression in esophageal squamous cell carcinoma. Oncology 2006, 70:378-389.

21. ten Haaf A, Bektas N, von Serenyi $S$, et al: Expression of the gliomaassociated oncogene homolog (GLI) 1 in human breast cancer is associated with unfavourable overall survival. BMC Cancer 2009, 9:298-310.

22. Xu M, Li X, Liu T, et al: Prognostic value of hedgehog signaling pathway in patients with colon cancer. Med Oncol 2012, 29:1010-6.

23. Yan $M$, Wang $L$, Zuo $H$, et al: $H H / G L I$ signalling as a new therapeutic target for patients with oral squamous cell carcinoma. Oral Oncol 2011, 47:504-509.

24. Ikram MS, Neill GW, Regl G, et al: GLI2 is expressed in normal human epidermis and BCC and induces GLI1 expression by binding to its promoter. J Invest Dermatol 2004, 122:1503-1509.

25. Cheng WT, Xu K, Tian DY, et al: Role of Hedgehog signaling pathway in proliferation and invasiveness of hepatocellular carcinoma cells. Int J Oncol 2009, 34:829-836.

26. Kim Y, Yoon JW, Xiao $X$, et al: Selective down-regulation of gliomaassociated oncogene 2 inhibits the proliferation of hepatocellular carcinoma cells. Cancer Res 2007, 67:3583-3593.

27. Patil MA, Zhang J, Ho C, et al: Hedgehog signaling in human hepatocellular carcinoma. Cancer Biol Ther 2006, 5:111-117.

28. Sicklick JK, Li YX, Jayaraman A, et al: Dysregulation of the Hedgehog pathway in human hepatocarcinogenesis. Carcinogenesis 2006, 27:748-757.

29. Zhang D, Liu J, Wang Y, et al: ShRNA-mediated silencing of Gli2 gene inhibits proliferation and sensitizes human hepatocellular carcinoma cells towards TRAIL-induced apoptosis. J Cell Biochem 2011, 112:3140-3150.

30. Dai DL, Martinka M, Li G, et al: Prognostic significance of activated Akt expression in melanoma: a clinicopathologic study of 292 cases. J Clin Oncol 2005, 23:1473-1482.

31. Wang $Y$, Dai DL, Martinka M, et al: Prognostic significance of nuclear ING3 expression in human cutaneous melanoma. Clin Cancer Res 2007, 13:4111-4116.

32. Eichberger $T$, Sander $V$, Schnidar $H$, et al: Overlapping and distinct transcriptional regulator properties of the GLI1 and GLI2 oncogenes. Genomics 2006, 87:616-632.

33. Grachtchouk V, Grachtchouk M, Lowe L, et al: The magnitude of hedgehog signaling activity defines skin tumor phenotype. EMBO J 2003, 22:2741-2751.

34. Kump E, Ji J, Wernli M, et al: Gli2 upregulates cFlip and renders basal cell carcinoma cells resistant to death ligand-mediated apoptosis. Oncogene 2008, 27:3856-3864.

35. Regl G, Kasper M, Schnidar H, et al: Activation of the BCL2 promoter in response to Hedgehog/GLI signal transduction is predominantly mediated by GLI2. Cancer Res 2004, 64:7724-7731.

36. Fulda S, Meyer E, Debatin KM: Inhibition of TRAIL-induced apoptosis by BCl-2 overexpression. Oncogene 2002, 21:2283-2294.

37. Jin CY, Park C, Moon SK, et al: Genistein sensitizes human hepatocellular carcinoma cells to TRAIL-mediated apoptosis by enhancing Bid cleavage. Anticancer Drugs 2009, 20:713-722.

38. Okano H, Shiraki K, Inoue H, et al: Cellular FLICE/caspase-8-inhibitory protein as a principal regulator of cell death and survival in human hepatocellular carcinoma. Lab Invest 2003, 83:1033-1043.

39. Lin M, Guo LM, Liu H, et al: Nuclear accumulation of glioma-associated oncogene 2 protein and enhanced expression of forkhead-box transcription factor $\mathrm{M} 1$ protein in human hepatocellular carcinoma. Histol Histopathol 2010, 25:1269-1275.

40. Blanco MJ, Moreno-Bueno G, Sarrio D, et al: Correlation of Snail expression with histological grade and lymph node status in breast carcinomas. Oncogene 2002, 21:3241-3246.

41. Ramis-Conde I, Drasdo D, Anderson AR, et al: Modeling the influence of the E-cadherin-beta-catenin pathway in cancer cell invasion: a multiscale approach. Biophys J 2008, 95:155-165.

42. Zheng $X$, Yao $Y, X u$ Q, et al: Evaluation of glioma-associated oncogene 1 expression and its correlation with the expression of sonic hedgehog, Ecadherin and S100a4 in human hepatocellular carcinoma. Mol Med Report 2010, 3:965-970.

43. Barrallo-Gimeno A, Nieto MA: The Snail genes as inducers of cell movement and survival: implications in development and cancer. Development 2005, 132:3151-3161.

44. Castro Alves C, Rosivatz E, Schott C, et al: Slug is overexpressed in gastric carcinomas and may act synergistically with SIP1 and Snail in the downregulat ion of E-cadherin. J Pathol 2007, 211:507-515. 
45. Katoh M: Epithelial-mesenchymal transition in gastric cancer (Review). Int J Oncol 2005, 27:1677-1683.

46. Lee JM, Dedhar S, Kalluri R, et al: The epithelial-mesenchymal transition: new insights in signaling, development, and disease. J Cell Biol 2006, 172:973-981.

47. Rosivatz E, Becker I, Specht $K$, et al: Differential expression of the epithelial-mesenchymal transition regulators snail, SIP1, and twist in gastric cancer. Am J Pathol 2002, 161:1881-1891.

48. Zheng X, Rumie Vittar NB, Gai X, et al: The transcription factor GLI1 mediates TGF $\beta 1$ driven EMT in hepatocellular carcinoma via a SNAl1dependent mechanism. PLoS One 2012, 7:e49581.

49. Thiery JP, Acloque $H$, Huang RY, et al: Epithelial-mesenchymal transitions in development and disease. Cell 2009, 139:871-890.

50. Alexaki VI, Javelaud D, Van Kempen LC, et al: GLI2-mediated melanoma invasion and metastasis. J Natl Cancer Inst 2010, 102:1148-1159.

doi:10.1186/1477-7819-11-25

Cite this article as: Zhang et al:: Expression of glioma-associated oncogene 2 (Gli 2) is correlated with poor prognosis in patients with hepatocellular carcinoma undergoing hepatectomy. World Journal of Surgical Oncology 2013 11:25.

\section{Submit your next manuscript to BioMed Central and take full advantage of:}

- Convenient online submission

- Thorough peer review

- No space constraints or color figure charges

- Immediate publication on acceptance

- Inclusion in PubMed, CAS, Scopus and Google Scholar

- Research which is freely available for redistribution 